\title{
INFORMES
}

\section{NOTAS ACERCA DEL PROBLEMA DE LA VIVIENDA EN AMERICA LATINA}

\author{
OSCAR NúÑEZ \\ Emilio Pradilla CoBos \\ MaRTHa SchteIngart \\ El Colegio de México
}

\section{INTRODUCCIÓN}

EN América Latina la investigación referida al campo de la sociología urbana y la vivienda no ha tenido hasta el presente un gran desarrollo, sobre todo desde la perspectiva del análisis marxista.

Las limitaciones impuestas a la investigación social en general, como consecuencia del propio subdesarrollo imperante y de las condiciones politicas vigentes en la mayor parte de los países de la región, se han hecho sentir también en los estudios urbanos marxistas.

Unos cuantos centros de investigación o investigadores individuales, con grandes dificultades, escasa continuidad y relativo aislamiento, han comenzado hace muy pocos años a trabajar dentro de esta línea.

Así, se han realizado pocos estudios parciales, referidos a algunos países del área, lo que configura una situación en la cual resulta imposible presentar un panorama general, a nivel latinoamericano, de los distintos aspectos involucrados en el problema de la vivienda.

Esta situación se ha visto reflejada, en cierta medida, en el seminario latinoamericano efectuado en México con el objeto de presentar conclusiones para el Comité de Investigación: Sociología del Desarrollo Regional y Urbano del Ix Congreso Mundial de Sociología (Uppsala-Suecia). ${ }^{\circledR}$

1 El Seminario "El problema de la vivienda en América Latina", auspiciado por El Colegio de México, se celebró del 19 al 22 de junio de 1978 con la asistencia de 
A pesar de haber constituido un marco relevante de discusión y de contacto entre investigadores latinoamericanos empeñados en una misma orientación de los estudios relativos a la vivienda en América Latina, este Seminario sólo permitió obtener conclusiones parciales sobre los aspectos considerados, para algunos países latinoamericanos.

En consecuencia, el documento que aquí presentamos consta de una primera parte general, referida a la problemática social latinoamericana y de su incidencia sobre los aspectos más notorios del problema de la vivienda, contexto necesario (elaborado por los autores de este documento) para poder ubicar las conclusiones parciales surgidas del seminario, las cuales se exponen en la segunda parte.

\section{Aspectos generales del problema de la vivienda eN América latina}

Es evidente que las condiciones de las masas trabajadoras latinoamericanas, en lo que respecta a la vivienda, los servicios e infraestructura y al medio ambiente, no solamente son miserables sino que además tienden a agravarse con el correr de los años.

Para los autores de este comentario tal proceso de deterioro es efecto de la articulación de tres aspectos básicos que serán desarrollados sistemáticamente a continuación:

a) La pauperización de las masas trabajadoras;

b) Las condiciones en que el capital privado produce la vivienda-mercancía $\mathrm{y}$;

c) La forma como se da la participación del Estado en el campo habitacional.

\section{a) Pauperización de las masas trabajadoras}

Con excepción de México ${ }^{2}$ y algunas coyunturas temporales en países como Bolivia, Guatemala, Chile y Perú, ${ }^{3}$ el desarrollo capitalista en la agricultura se ha caracterizado por la transformación de la gran propiedad precapitalista en explotaciones capitalistas y la más aguda opresión política y expropiación del campesinado parcelario. Impulsado por el mercado mundial de materias primas agrícolas, por la industrialización y el crecimiento urbano, este desarrollo capitalista determina la rápida pauperización del campesinado parcelario $y$, al no proletarizar sino una parte limitada de éste, expulsa del sector agrícola a una masa creciente de población

11 investigaciones de diferentes países latinoamericanos. La lista de los documentos presentados al seminario se incluye al final.

2 Como consecuencia de la reforma agraria conquistada por la revolución mexicana de 1910-1917, aplicada fundamentalmente por Lázaro Cárdenas y revertida parcialmente a partir de los años cincuenta.

${ }^{3}$ Bolivia con la revolución de 1952, Guatemala durante el régimen de Arbenz de 1952 a 1954, Chile durante el gobierno de la Unidad Popular de 1970 a 1973 y Perú durante el Régimen de Velasco Alvarado, de 1968 a 1975, los cuales impulsan reformas agrarias democráticas, revertidas posteriormente. 
convertida en superflua para la producción, constituyendo lo fundamental de las migraciones campo-ciudad. A este proceso viene a sumarse la pauperización generada por el incremento demográfico sobre las formas precapitalistas de producción desarrollada en los minifundios, las comunidades indígenas y las tierras explotadas bajo formas de aparcería.

Desde sus inicios, ubicados en diferentes momentos históricos según los países, esta migración campesina y la descomposición de cierta producción artesanal urbana, han suministrado a la industria un "ejército de reserva"* de magnitud considerable que ha jugado un papel importante en la acumulación de capital, al presionar para que el valor de la fuerza del trabajo urbano se ubique muy cerca del nivel fisiológico de subsistencia del campesinado. Esta situación objetiva, unida a la debilidad del movimiento obrero, a su dispersión, a su control frecuente por parte del Estado, a la represión ejercida por diferentes regímenes dictatoriales, permite explicar el lento crecimiento de los salarios obreros y del conjunto de los salarios urbanos.

La rapidez de la descomposición del campesinado parcelario, la aceleración del proceso migratorio, el aumento masivo del "ejército de reserva industrial", se incrementan en el periodo de la segunda posguerra, cuando la restructuración del mercado mundial capitalista, la penetración masiva del capital imperialista (en particular el norteamericano) y el desarrollo de un sector de capital monopolista financiero, llevan a un rápido proceso de concentración-centralización monopólica del capital industrial, a la elevación de la composición orgánica del capital industrial y agrario y a la fusión del capital local e imperialista en una unidad, no sin contradicciones secundarias. Estos procesos, unidos al carácter lento y cíclico de acumulación de capital en América Latina, dan como resultado que tanto la producción industrial y agraria, como otros sectores económicos reduzcan relativamente la masa de fuerza de trabajo que pueden absorber.

$\mathrm{Si}$ a esto se añade el hecho que el desarrollo del capitalismo agrario y su correlato de expulsión campesina avanzan más o menos con rapidez arrojando masas enormes de campesinos hacia las ciudades, se pueden apreciar con claridad las determinaciones de la gran magnitud del "ejército de reserva" existente en las grandes ciudades latinoamericanas y sus efectos sobre el mantenimiento de bajos niveles salariales para las masas trabajadoras urbanas.

En los últimos dos decenios, la relativa saturación del proceso de indus-

"Se usa aquí el término "ejército industrial de reserva" en lugar de "población marginal" más comúnmente usada en América Latina ya que este último lleva implícito una concepción funcionalista de la sociedad. Sin embargo, es necesario aclarar que en los países latinoamericanos la población "liberada" de diversas formas sobrepasa con mucho los límites de lo que podría ser un "ejército industrial de reserva" (en el sentido de una palanca de la acumulación), ya que en gran parte no llega a ser absorbida, ni siquiera por breves temporadas, por la industria capitalista, sino que vegeta entre la artesanía tradicional, el trabajo en la parcela, nuevas formas de artesanía y subsumidas por el capital, servicios a las clases medias y burguesas, pequeño comercio ambulante, etc. Se trata de un desempleo o un subempleo que sobrepasa la población relativa que necesita el capital para sus ciclos de depresión o auge. Este tema ha sido motivo de serias discusiones teóricas sobre todo hacia fines de los años sesenta, y aún hoy continúa sin ser aclarado. 
trialización sustitutiva, así como la saturación relativa del mercado mundial de algunos productos agrícolas, el aumento de la magnitud de las inversiones necesarias a la ampliación del aparato productivo, los efectos de las crisis del capitalismo mundial y de las propias, la estrechez de los mercados internos, $y$ la necesidad de exportar manufacturas baratas, entre otras determinaciones estructurales, han llevado a la acentuación de una "pauta" de desarrollo capitalista que se apoya en forma marcada sobre la agudización de las condiciones de explotación de la clase obrera y las masas trabajadoras, el estancamiento o la reducción de los salarios y, en determinados periodos, a la sobrexplotación de la clase obrera como mecanismo compensatorio de la caída de la tasa de ganancia, todo ello en presencia de violentos procesos inflacionarios, que dan lugar a un agudo proceso de pauperización de la clase obrera y demás asalariados. Estas condiciones de la acumulación capitalista, unidas a la agudización de la lucha de clases (en la que después de un periodo caracterizado por las luchas campesinas viene a colocarse el movimiento obrero como punta de lanza) están en la base del desarrollo de la nueva tendencia antidemocrática, reaccionaria y en ocasiones fascistizante, de los regímenes políticos latinoamericanos que parece inaugurarse en 1964 en el Brasil, y que recorre toda América Latina desde entonces, incluidos regímenes formalmente democráticos. Estos regímenes desarrollan una política de supresión de los derechos de organización sindical y huelga de los obreros y asalariados, de represión y encarcelamiento o liquidación física de la vanguardia obrera $y$, por lo tanto, de castración de la lucha defensiva de los asalariados, que a la vez que permite y apoya el afianzamiento de las pautas de acumulación, actúa sobre el ya citado proceso de pauperización de las masas trabajadoras. Los ejemplos extremos de esta situación los encontramos en Chile, Argentina y Uruguay.

\section{b) Producción de la vivienda-mercancía por el capital privado}

Es posible afirmar, de manera general, que en América Latina se ha estado desarrollando en los últimos años un sector inmobiliario capitalista más o menos avanzado e importante según los países, en cuya consolidación la acción del Estado ha tenido una considerable influencia, sobre todo a través del financiamiento de la demanda y el apoyo a las empresas constructoras.

Pero el papel creciente jugado por el capital monopolista financiero dentro de este sector ha contribuido a hacer inaccesibles las viviendas producidas a través del mismo para la mayoría de la población trabajadora.

Sin embargo, a pesar de que estas viviendas están dirigidas a un grupo minoritario de la población, el funcionamiento del sector capitalista puede fijar condiciones que alteran el funcionamiento de otros sistemas de producción. Así, la producción no capitalista de la vivienda o la autoconcentración tendrían que pagar su tributo al mercado capitalista del suelo urbano, como consecuencia de los probables usos capitalistas que podría tener el suelo sobre el cual esa producción se apoya. Así, es posible afirmar que la misma existencia de las colonias proletarias o asentamientos populares es consecuencia del funcionamiento del sector inmobiliario más avanzado y de sus efectos sobre la acumulación de capital y la reproducción de la fuerza de trabajo en el marco de formaciones sociales donde, como he- 
mos visto, se da una gran explotación de la clase obrera y la existencia de un enorme "ejército industrial de reserva".

\section{c) La acción del Estado en el campo habitacional}

En general, las políticas habitacionales del Estado en América Latina, más que resolver el problema de los sectores más necesitados de la población se han limitado a incrementar la oferta de vivienda, acelerando el desarrollo capitalista del sector de la construcción, favoreciendo a intereses inmobiliarios y transformando en demanda solvente las necesidades habitacionales de las capas medias.

De esta manera, salvo algunas coyunturas excepcionales de gobiernos populares o populistas en los que se relevó el aspecto "social" de la política de vivienda prestándose mayor atención al aspecto de la reproducción de la fuerza de trabajo, en general en América Latina los diferentes regímenes políticos han privilegiado, a través de sus políticas habitacionales, la reproducción del capital en general y el vinculado en la construcción en particular.

En síntesis, parece evidente entonces que el deterioro de las condiciones de vivienda y servicios de las masas trabajadoras urbanas latinoamericanas es consecuencia de que las viviendas-mercancías producidas por el sector capitalista inmobiliario, y aquéllas cuya producción es promovida por los Estados y sus instituciones especializadas, se enfrentan, en el mercado, a una mayoría de la población urbana compuesta por obreros y asalariados pauperizados y por una gran masa de desempleados o subempleados que reciben ingresos sólo ocasionalmente, en cantidades que escasamente cubren las necesidades biológicas mínimas de subsistencia. Esta mayoría de la población no es "demanda solvente", ni "sujeto de crédito", para las viviendas puestas en el mercado en venta o en alquiler, por el sector capitalista privado o el Estado.

\section{Conclusiones del. Seminario}

Expondremos a contituación algunas conclusiones del seminario referidas a los tres temas principales desarrollados en las ponencias presentadas: el sector privado de la construcción, las políticas del Estado y las formas de vivienda para las masas trabajadoras. Como se aclaró al comienzo de este documento, estas conclusiones sólo tendrían un carácter parcial, referido a unos pocos países latinoamericanos, dadas las condiciones en que se está desarrollando la investigación en la región.

\section{El Sector privado de la construcción en algunos países de América Latina}

Los tres trabajos presentados en el seminario sobre el sector privado de la construcción (referidos a Venezuela, Colombia y México), coinciden en afirmar que el sector inmobiliario capitalista avanzado o la construcción promocional privada, tiende a reemplazar a la construcción por encargo, ${ }^{5}$

- La producción por encargo está caracterizada por el hecho de que quien ejerce el control económico de la producción es al mismo tiempo el usuario final, mien- 
sobre todo a partir de los años sesenta. En el caso de Colombia parece que existieron mayores impedimentos para el desarrollo de este sector avanzado, que recién se impone en los últimos años. La construcción promocional privada, caracterizada por la relación capital-trabajo asalariado, por su objetivo de acumulación de capital a través de la apropiación de la plusvalía generada por los obreros del sector, por implicar una producción para el mercado y procesos productivos repetitivos y continuos, sólo puede desarrollarse a partir de la superación de ciertas limitaciones básicas:

a) La existencia de un mercado estrecho (debido al tamaño reducido de la ciudad y a la pauperización que elimina de la demanda solvente a un sector importante de la población);

b) La debilidad de los mecanismos financieros (que podrían ampliar las capas con posibilidades de acceso a la propiedad);

c) La existencia de un gran sector por encargo que le disputa posibles clientes;

d) La ausencia de grandes empresas constructoras con técnicas avanzadas que permitan al capital promocional reducir sus costos y contrarrestar la competencia de la construcción por encargo.

En consecuencia, el crecimiento urbano, la relativa expansión de la economía que eleva el poder adquisitivo de nuevas capas sociales, la sustitución de importaciones y la atenuación de las dificultades para proveer ciertos bienes de capital y materiales de construcción, la evolución de los mecanismos financieros y la intervención del Estado, han sido las causas principales que han incidido en la expansión del sector inmobiliario capitalista avanzado. Sin embargo, la producción por encargo o la autoconstrucción son todavía predominantes, y se aplican tanto a sectores de elevados ingresos como a las grandes mayorías que no tienen acceso a la vivienda producida por el sector capitalista. Por ejemplo, en México el $65 \%$ de las familias de menores ingresos autofinancian y en gran medida autoconstruyen su vivienda, fuera del sistema inmobiliario privado y de la provisión habitacional del Estado.

En cuanto al origen del capital de promoción y a las características de los grandes promotores, se señalan en general a aquellos que han obtenido su capital del manejo de la tierra (urbanizadores y propietarios de tierra periférica) y a los capitalistas que canalizan capitales al sector de la promoción inmobiliaria desde otras ramas de la producción. En este último caso parecería que el carácter monopólico y concentrado de la producción en ciertas ramas, así como la estrechez de los mercados, podrían determinar la existencia de excedentes de acumulación difícilmente reinvertidos en la esfera de la operación normal de esos capitales.

La construcción promocional se convierte en una oportunidad muy atractiva de inversión debido a su elevada rentabilidad y por el hecho de que el capital del promotor es un capital de circulación que no se comprome-

tras el que ejerce el control técnico es un agente distinto (constructor). Si bien esta producción no es para el mercado (es un valor de uso), el bien puede entrar a la esfera de la circulación mercantil, ya sea bajo la forma de arrendamiento o venta. 
te con capital fijo. Mientras en el caso de Colombia parecería que estos últimos capitales no tienen control sobre los terrenos periféricos para sectores solventes y se orientan por lo tanto hacia el centro de la ciudad en operaciones de renovación urbana, en el caso de México se ha observado que este tipo de capitales (provenientes de la industria) se invierten en la promoción de grandes fraccionamientos periféricos. En cambio se ha observado que la promoción de conjuntos habitacionales más centrales tiene en México una mayor incidencia de las grandes empresas constructoras y los principales bancos del país (el capital financiero monopólico). Es probable que la existencia de grandes terratenientes en la periferia de las ciudades cree un monopolio de la tierra tanto en Colombia como Venezuela, mientras que en el caso mexicano, los efectos de la reforma agraria hayan producido situaciones muy diferentes en cuanto a la apropiación del área de expansión de la ciudad.

En general, para el caso de México se ha señalado que la gran dependencia del capital financiero monopólico, en la que se basa la lógica de las operaciones inmobiliarias, ha generado un proceso de monopolización de la producción, por el cual pocas grandes empresas prosperan absorbiendo en algunos casos a las menores. Los controles crecientes ejercidos por el Estado han coadyuvado en la acentuación de ese proceso de monopolización.

El estudio referido a Venezuela y centrado más en la industria de la construcción, pone de relieve las elevadas tasas de ganancia obtenidas por este sector, así como el hecho de que las ganancias obtenidas en otras ramas de la economía son aumentadas velozmente en la producción de edificios, sobre todo en ciertas coyunturas de auge de la construcción. Asimismo, se afirma que el Estado contribuye de manera significativa al avance de las fuerzas productivas en la rama de la construcción, apoyando la incorporación progresiva de la mecanización y la utilización de equipo y herramientas más sofisticados, proceso que acompaña al desarrollo de la construcción promocional. Las propias empresas constructoras amplían las actividades entrando también a la promoción inmobiliaria.

\section{Las intervenciones del Estado en materia de vivienda}

En todos los países de América Latina, el Estado ha venido realizando programas de vivienda limitados en favor de sus empleados y de los trabajadores de sus empresas ya desde el segundo decenio de este siglo. Sin embargo estos programas, con excepción de los llevados a cabo por los regímenes populistas, han tenido escasos resultados.

Es hasta los años 60 cuando se da una importante intervención del Estado en materia de vivienda, que a través del impulso de este tipo de producción busca obviar los crecientes problemas causados por los procesos acumulativos, que en mayor o menor grado sufren todos los países latinoamericanos. Preocupados con la amenaza de estancamiento que pronostican organismos como la CEPAL, se organizan diferentes y nuevos sistemas financieros de capital "combinados" (estatal y privado), que buscan hacer posible la producción masiva de vivienda.

En los años setenta, la intervención del Estadó crecerá con la creación, en México, Venezuela, Guatemala, Colombia, etc., de nuevos organismos 
estatales caracterizados por una más importante intervención financiera del Estado, que a través de leyes impositivas nuevas logrará la creación de fondos cuantiosos de financiamiento y promoción de vivienda para asalariados, caracterizados por su combinación con capitales privados e internacionales.

Por ello, en principio, serán instrumentos más poderosos y centralizados, que buscan incidir en los principales "cuellos de botella" de las economías latinoamericanas en crisis. La producción de vivienda crecerá de manera considerable aunque no de acuerdo ni a los recursos captados (debido en muchos casos a la irracional utilización de los mismos, ni al déficit acumulativo de la demanda.

Se logrará el acceso de nuevas capas de asalariados al mercado de la vivienda gracias a los sistemas de crédito, sin lograrse avances significativos en materia de precios de venta. Más importantes serán los resultados en materia de empleo y en el impulso que se le dará a la industria de la construcción. Para los Estados no serán necesariamente realizaciones que favorezcan su legitimación, debido al desencanto que sufrirán los trabajadores asalariados al contemplar la desproporción entre las expectativas creadas y el monto real de viviendas producidas.

\section{Las formas de vivienda para las masas trabajadoras.}

En las grandes ciudades latinoamericanas, una parte mayoritaria de la población resuelve su necesidad de vivienda mediante el recurso a lo que denominamos "formas de subsistencia" que no corresponden a la norma de "vivienda socialmente necesaria". Desde el punto de vista de su valor de uso, esas viviendas se caracterizan por: el hacinamiento y la promiscuidad, la insalubridad, la ausencia de servicios básicos (agua, luz, drenaje, servicios sanitarios) y de equipamiento urbano (vialidad, escuelas, equipos de salud, etc.), la debilidad estructural y la inestabilidad; por lo tanto ellas no sirven para la adecuada reproducción ampliada de la fuerza de trabajo.

La forma más tradicional de vivienda para las masas trabajadoras la constituye el inquilinato central. ${ }^{6}$ En él, una familia obtiene, mediante la entrega de una parte considerable de sus ingresos, el derecho al uso de un cuarto, por lo general sin iluminación ni ventilación, en una estructura antigua y deteriorada, con acceso sólo a servicios colectivos de pésima calidad e higiene. El casateniente, que ya ha amortizado hace años la inversión realizada en su construcción, se apropia fundamentalmente de rentas del suelo extraídas bajo una forma claramente usuraria al inquilino. Sin embargo, esta forma "central" tiende a reducirse más o menos con rapidez debido a la saturación de los locales centrales disponibles, a la competencia con otros usos urbanos más rentables tales como el comercio, las oficinas y los "parkings", a la destrucción total de los inmuebles o al avance de los procesos de renovación de las áreas centrales. En su lugar, se desarrolla el alquiler de cuartos en colonias populares periféricas a aquellos que no están en condiciones económicas de acceder ni a la vivienda adecuada,

6 Inquilinatos, casas de vecindad, conventillos, palomares, mesones, cómodos de cortiso, pensiones, etc., según las distintas denominaciones populares. 
ni a otras formas de subsistencia; esto lleva a desarrollar contradicciones al interior de las masas trabajadoras mismas, ya que el arrendador, muchas veces de la misma clase social del inquilino, extrae a éste una parte considerable de su fondo de subsistencia, a fin de incrementar el suyo propio.

Sin embargo, una forma muy desarrollada en la actualidad es la "autoconstrucción" en cualquiera de sus múltiples variedades. Las características esenciales de la "autoconstrucción pueden resumirse así: El terreno es adecuado y la construcción realizada por el mismo usuario, mediante un alargamiento de su jornada de trabajo y la integración de trabajo familiar; cuando utiliza el trabajo de otros constructores es en magnitud limitada y secundaria o como un simple sustituto de su propio tiempo de trabajo. Puesto que no se da una relación capital-trabajo asalariado tendiente a valorizar un capital nos encontramos frente a una forma de producción no capitalista, los instrumentos de trabajo utilizados son mínimos y rudimentarios y el peso del proceso recae sobre la habilidad (comúnmente casi nula) del autoconstructor.

Las materias primas son a veces de deshecho o de segunda mano lo cual da lugar a estructuras inestables e inadecuadas a las necesidades.7 El proceso de trabajo se combina con el uso y se prolonga por varios años y a veces por generaciones enteras; lo anterior determina un predominio del componente fuerza de trabajo y, por tanto, un alto valor, superior al de viviendas similares producidas en otras formas. El proceso de trabajo y el control económico de él recaen sobre el autoconstructor y sólo aparecen como condicionantes externos el del mercado del suelo y el de la dotación de materiales y servicios públicos por parte del Estado.

Producida como valor de uso, la vivienda frecuentemente entra en forma total o parcial en los circuitos mercantiles, casi siempre a precios que se colocan por debajo de su valor. La autoadecuación del terreno y la autoconstrucción generan sin embargo nuevas rentas del suelo que benefician a todos los propietarios territoriales urbanos $y$, en particular a los del área de influencia. En síntesis, podemos afirmar que la autoconstrucción significa un alargamiento de la jornada de trabajo del obrero más allá de lo normal, que no es remunerado por el patrón. Cuando se trata de asalariados totales o parciales, implica un desgaste más acelerado de la fuerza de trabajo; mantiene el atraso de las fuerzas productivas en el sector y $\in$ s por lo tanto una forma que trae aparejada un desperdicio considerable del trabajo social y altos costos sociales, una drástica reducción del fondo de consumo de sus actores y se agudiza asimismo la dispersión y la anarquía urbanas.

La autoconstrucción requiere para su desarrollo de un suelo soporte el cual es obtenido de manera fundamental (aunque no exclusivamente) por la vía del fraccionamiento "ilegal" o la invasión de tierras públicas o privadas. La adquisición de un lote en un fraccionamiento ilegal, es decir, que no reúne las condiciones de equipamiento exigidas por el Estado o que presenta problemas de titularidad jurídica, permite al comprador evitar ciertos costos de inversión que no puede cubrir y también la evasión de ciertas condiciones contractuales (garantías de pago, hipotecas, demostra-

7 Pero también se utilizan materiales producidos en forma capitalista. 
ción de ingresos, etc.) pero lo somete al permanente peligro de lanzamiento y a la inseguridad jurídica. Para el fraccionador significa, por otra parte, la apropiación de rentas del suelo considerables sin que para ello haya tenido que realizar inversión alguna y, a la vez, la posibilidad de operar mediante la introducción al mercado de tierras comúnmente sin valor comercial alguno y sin posibilidades de realizar en ellos acciones de fraccionamiento normal; ello lleva a empresas fraccionadoras capitalistas a hacer incursiones también en este tipo de operaciones.

Para las masas más pauperizadas, carentes de ingresos aún para adquisición de un terreno en un fraccionamiento "ilegal", la única alternativa es la invasión de terrenos estatales o privados y para ello tendrá que correr los riesgos de la represión oficial. Éstos disminuirán si la inversión se realiza en terrenos de muy poca rentabilidad en el mercado, en suelos de nula construibilidad, lo cual revertirá en una laboriosa adecuación y en barreras adicionales a la instalación de servicios. Cada día, los Estados latinoamericanos reprimen más agudamente estas invasiones y bloquean así una de las pocas alternativas, la más "natural", que queda a las masas pauperizadas urbanas.

Tanto en las invasiones, como en los fraccionamientos "ilegales", los problemas centrales de los autoconstructores son la ilegalidad de sus títulos de propiedad que los coloca en la inseguridad, y la ausencia de servicios. Las luchas por la regularización de la propiedad y por la obtención de servicios son las dos reivindicaciones básicas levantadas por los pobladores en las frecuentes luchas reivindicativas, llenas de contradicciones, que los enfrentan al Estado. Este manipula y divide o reprime estas movilizaciones, a la vez que desarrolla la demagogia de la acción social y el desarrollo comunitario, haciendo recaer sobre los pobladores lo fundamental del costo de las acciones, recuperando parte o el total de las rentas del suelo no pagadas inicialmente y vinculando al mercado del suelo tierras inútiles para la urbanización y ahora valorizadas y adecuadas.

Pero el hecho más importante es que la autoconstrucción, efecto de la aguda situación de explotación y pauperismo de las masas, desgastadora de la fuerza de trabajo, se convierte en un mecanismo eficaz de apoyo a la acumulación de capital.

Conscientes de estas ventajas, los Estados latinoamericanos, y las agencias internacionales han promovido desde hace dos decenios y por múltiples caminos a la autoconstrucción; han permitido los fraccionamientos ilegales, han aceptado, o aún impulsado, las invasiones de tierras inútiles para otros fines, ${ }^{8}$ han aceptado la regularización de terrenos y la instalación de servicios en zonas irregulares, han desarrollado planes de lotes con o sin servicios con destino a la autoconstrucción, y más aún, han desarrollado planes completos de autoconstrucción.

En el momento actual el Banco Mundial, otros organismos internacionales y muchos Estados latinoamericanos presentan el impulso masivo a la autoconstrucción como el camino para la "solución" del problema de la vivienda de los sectores urbanos más pauperizados, a la vez que reducen los subsidios y hacen cada vez más próximas a la rentabilidad capitalista

8 Caso de los pantanos del suburbio de Guayaquil o de las colinas de Lima. 
sus programas dirigidos a los sectores medios de la población, reproduciendo asimismo la segregación social del habitat.

\section{Cuba: la excepción latinoamericana}

De los países latinoamericanos sólo Cuba escapa a la situación antes analizada. Allí la revolución socialista y la implantación de la dictadura del proletariado han creado las condiciones favorables para la paulatina solución del problema de la vivienda.

Estas condiciones pueden resumirse así: nacionalización de la mayor parte de la tierra urbana y urbanizable; control estatal sobre la industria de materiales de construcción y de la industria de la construcción misma; apropiación y aplicación, en beneficio de toda la sociedad, de la más moderna tecnología constructiva; participación masiva de los trabajadores de la construcción de vivienda mediante el trabajo volutario; implantación de procedimientos democráticos en la distribución de las viviendas producidas y desarrollo de una planeación urbana democrática, centralizada e impositiva, y claramente articulada a la planeación global.

Estas medidas unidas a la fijación de alquileres en forma proporcional al salario, han permitido avances importantes tanto en la solución del problema de la vivienda urbana, como un radical mejoramiento de la situación habitacional del campesinado y la disminución de la diferenciación campo-ciudad.

Sin embargo, el bloqueo establecido por el imperialismo americano ha venido a agravar seriamente la natural limitación de recursos disponibles, alargando el proceso de solución del agudo problema habitacional dejado como herencia por la dictadura de Batista.

El caso cubano constituye entonces una experiencia cuyo análisis es fundamental para quienes estudiamos este problema, en particular en lo relativo a las políticas de trabajo voluntario de las micro-brigadas, a la utilización de la moderna tecnología constructiva en la construcción masiva de vivienda, a la urbanización del campo, al desarrollo equilibrado y planeado de la urbanización; estas vías de solución se han hecho posibles por la destrucción de las relaciones capitalistas de producción.

El caso cubano muestra también, cómo, parafraseando a Engels, "solamente resolviendo la cuestión social por la vía de la revolución socialista es posible echar las bases firmes para la solución del problema de la vivienda".

\section{LISTA DE PONENCIAS PRESENTADAS AL SEMINARIO:}

\section{"El problema de la vivienda en América Latina"}

I. Notas sobre la industria de la construcción en Venezuela. Teolinda Bolívar y Alberto Lovera.

II. Apuntes para un estudio de las formas de producción del espacio construído en Bogotá. Samuel Jaramillo. 
III. El sector inmobiliario capitalista y las formas de apropiación del suelo urbano: El caso de México.

Martha Schteingart.

IV. El Salvador, 1932-1978. La crisis del Estado y el papel de las "políticas sociales" (Acerca de las funciones que cumplen las políticas de vivienda). Mario Lungo.

V. Notas para la introducción del referente socialista en la discusión de la cuestión urbana y del problema de la vivienda en América Latina.

Pedro G. Pascal y Ramón Poblete.

VI. La vivienda en Cuba Revolucionaria: Síntesis de factores significativos en su evaluación y participación de la comunidad en su solución.

Luz Alquimia Peña.

VII. Autoconstrucción, explotación de la fuerza de trabajo y política del Estado en América Latina.

Emilio Pradilla Cobos.

VIII. Explotación y reproducción de la fuerza de trabajo. (Notas sobre el problema de la vivienda urbana en el Brasil). Lucio Kowarick.

IX. INFONAVIT. Un sistema corporativo para asalariados bajos. Oscar Núñez.

X. Notas para la discusión del problema de la vivienda en América Latina. El caso de Guayaquil. Gaytán Villavicencio y Alfredo Rodríguez.

XI. El desarrollo capitalista de Guatemala y la cuestión urbana. Luis Alvarado. 